\title{
Personality and Cross-Cultural Adjustment among Expatriate Assignees in Malaysia
}

\author{
Subramaniam Sri Ramalu (corresponding author) \\ College of Business, Universiti Utara Malaysia, 06010 UUM Sintok Kedah, Malaysia \\ Raduan Che Rose \\ Department of Management and Marketing, Faculty of Economics and Management \\ Universiti Putra Malaysia, 43400, UPM SERDANG, Selangor, Malaysia \\ E-mail: rcr@econ.upm.edu.my \\ Jegak Uli \\ Department of Professional Development and Continuing Education
}

Faculty of Educational Studies, Universiti Putra Malaysia, 43400, UPM SERDANG, Selangor, Malaysia

E-mail: jegak@ace.upm.edu.my

Naresh Kumar

Department of Management and Marketing, Faculty of Economics and Management

Universiti Putra Malaysia, 43400, UPM SERDANG, Selangor, Malaysia

E-mail: naresh@econ.upm.edu.my

\begin{abstract}
This paper investigates the affects of personality traits on expatriate cross-cultural adjustment. Based on sample of 332 expatriates working in Malaysia, personality factor found to be a significant determinant of expatriate cross-cultural adjustment in international assignments. Specifically, the results of this study reveal that expatriates in Malaysia with greater agreeableness personality fared better in their general and interaction adjustment. Those with greater extraversion found to adjust better in general environment. Those with greater conscientiousness and openness to experience adjusted better to the work environment. The findings of this study contributes to the body of knowledge in the cross-cultural management field and have practical implication to expatriating firms especially in the area of selection and training of candidates for international assignments.
\end{abstract}

Keywords: Personality, Cross-Cultural Adjustment, Expatriate

\section{Introduction}

The economic globalization has witnessed MNCs effort to increase their international activity and presence (Maertz, Hassan \& Magnusson, 2009). This effort requires presence of globally competent workforce, and with it, the intensive use of expatriates. Expatriates identified as sojourner who leaves his or her country, under assignment, for business purpose, with the intent of eventual return (Aycan \& Kanungo, 1997). Global Relocation Trends Survey (2008) conducted by GMAC Global Relocation Services reported that 67 per cent of companies have increased the size of their current international assignee population compared to 31 per cent in 2004.

The extensive use of expatriates, however, has created challenges for MNCs to manage expatriate assignments. This is because, firstly, the cost of sending expatriates and their families abroad are extremely high. For example, a three-year assignment for one expatriate estimated to cost approximately one million dollars (Allerton, 1997). Secondly, the rate of expatriate failure is alarming. A variety of studies examining the premature return of mostly American expatriates found that between 16 and 40 per cent of all assignment terminated early (Caligiuri, 1997). In addition to quantifiable cost, there are additional cost associated with lost business opportunities, reduced productivity, and damage corporate relationship that in the long run could cost the MNCs much more (Storti, 2001).

It is for these reasons that research on expatriate cross-cultural adjustment (CCA) has gained considerable attention (e.g., Tung, 1987; Black, Mendenhall, \& Oddou, 1991; McEvoy \& Parker, 1995; Black \& Gregersen, 1999; Shaffer, Harrison \& Gilley, 1999; Takeuchi, Yun \& Tesluk, 2002). Generally, the results of these studies 
indicated that if expatriates do not adjust well to the host culture, they might depart prematurely (Tung, 1982; Black \& Stephens, 1989; McEvoy \& Parker, 1995). Others may remain in the assignment and demonstrate poor job performance due to dysfunctional adjustment (Kraimer, Wayne \& Jaworski, 2001; Shaffer, Harrison, Gregeren, Black \& Ferzandi, 2006).

Research identifying the correlates/predictors of expatriate CCA found factors related to individual, job, organizational, and situational are important contributing elements (Black et al., 1991; Shaffer, Harrison \& Gilley, 1999; Bhaskar-Shrinivas, Harrison, Shaffer \& Luk, 2005). In this research realm, individual differences of personality trait appear to gained considerable attention (Caligiuri, 2000b; Ward, Leong \& Low, 2004; Huang, Chi \& Lawler, 2005; Swagler \& Jome, 2005; Shaffer et al., 2006). Personality trait believed to be a reliable predictor of workplace behavior in the international setting similar to what has found in domestic research. The recent emergence of a unified, well-developed theory of personality, referred to as the Big Five Personality (Costa \& McCrae, 1992) particularly has provided the opportunity to test the relationship between personality and expatriate CCA.

This paper is concerned with how personality trait affects the CCA of expatriates assigned to Malaysia. Although a number of studies have been conducted on the relationship between personality and CCA (Caligiuri, 2000b; Ward et al., 2004; Huang et al., 2005; Swagler \& Jome, 2005; Shaffer et al., 2006), it is still uncertain whether personality factor is the determinant of CCA. Moreover, in exception to Tahir and Ismail (2007), no study conducted in Malaysia. We believe that expatriate population in Malaysia is worth investigating, particularly because the country has become one of the preferred FDI destinations in the South East Asia region (MIDA, 2009). This indicates that the country will have to face a continuous increase in number of expatriates admitted to various sectors of employment. There were 35,583 approved expatriate postings in Malaysia in year 2007 alone (Malaysia, 2008). The growing trend in the number of expatriates and international assignments in Malaysia has heightened the need for research to understand how expatriates adapt and perform during their assignments in Malaysia. The purpose of this study therefore is to investigate how personality related to CCA of expatriates assigned to Malaysia.

\section{Literature Review}

\subsection{Personality}

Personality defined as enduring emotional, interpersonal, experiential, attitudinal, and motivational style that explains individual's behavior in different situations (McCrae \& Costa, 1989). A review of the Industrial/Organizational psychology literature suggests that the sum of all personality characteristics can be categorize in five basic trait dimensions- extraversion, conscientiousness, agreeableness, openness to experience and neuroticism. These five trait dimensions subsequently labeled as the Big Five Personality (Hough, 1992; Digman, 1997).

The first dimension, extraversion, has been related with heightened level of sociability. Individuals high on extraversion tend to like groups and gatherings, to be talkative and energetic and generally to be more active and assertive (Costa \& McCrae, 1992). An extravert person considered sociable and outgoing with others (Huang et al., 2005). Conscientiousness dimension described as a form of conformity to rules and standards, and linked to traits like responsibility, organization, hard work, impulse control, and prudence (Barrick \& Mount, 1991; Hogan \& Ones, 1997). Individuals high on conscientiousness is also dependable and trustworthy (Costa \& McCrae, 1992). The third dimension, agreeableness has been associated with conformity with others and friendliness in the interpersonal setting (Hogan \& Hogan, 1986; Digman, 1990). Individuals high on agreeableness tend to be more helpful and sympathetic towards others, as well as more trusting of the intentions of other people (Costa \& McCrae, 1992). According to Laursen, Pulkkinen and Adams (2002), agreeableness trait related to higher levels of social compliance and self-control, and lower levels of aggression. The fourth dimension, openness to experience appears to be a personality trait that reflects individuals' habitual willingness to try new ideas, tolerate ambiguity and dissonance, and generally be curious and eager to learn (Barrick \& Mount, 1991). Individuals high on openness to experience tend to be open minded, original in thought, intelligent, imaginative, and non-judgmental. Finally, neuroticism personality is associated with lessened emotional control and stability (Mount \& Barrick, 1995). Neurotic individuals tend to have relatively negative core self-evaluations, leading to emotional distress and associated behaviors (Rusting \& Larsen, 1998). Neuroticism also related to a person's general tendency to experience negative effects such as fear, sadness, embarrassment, anger, guilt, and disgust (Dalton \& Wilson, 2000). 
Albeit limited, the available studies have linked personality factor with various expatriate outcomes such CCA (Shaffer et al., 2006), job performance (Mol, Born, Willemsen \& Van Der Molen, 2005) and premature return from assignment (e.g., Caligiuri, 2000a).

\subsection{Cross-Cultural Adjustment}

Cross-cultural adjustment conceptualized as the degree of psychological comfort an expatriate has with the various aspects of a host culture (Black \& Stephens, 1989; Gregersen \& Black, 1990). Three specific areas of CCA distinguished in the literature (Black \& Stephens, 1989): Adjustment to (1) general environment (degree of comfort with general living conditions, such as climate, health facilities, and food); (2) interaction with host country nationals; and (3) work (performance standards, job, and supervisory responsibilities).

Cross-cultural adjustment suggested as a key determinant of expatriate success in their international assignments. Past research indicated that CCA is a temporal and primary outcome in an expatriate's assignment that would influence the development of secondary or more distal expatriate adjustment. Among the spillover effects of CCA are strain (e.g., Hechanova, Beehr \& Christiansen, 2003), job satisfaction (e.g., Takeuchi, Yun, \& Tesluk, 2002), organizational commitment (e.g., Nauman, 1993; Shaffer \& Harrison, 1998), job performance (e.g., Shay \& Baack, 2006; Kim \& Slocum, 2008), and premature return from assignment (e.g., Black \& Stephens, 1989; Hechanova et al., 2003).

\subsection{Hypotheses Development}

Considerable research has indicated a relationship between personality factor and CCA (e.g., Ali, Van der Zee \& Sanders, 2003; Ward et al., 2004; Huang et al., 2005; Swagler \& Jome, 2005; Shaffer et al., 2006). In general, these results show that certain personality traits positively related to CCA. Emotional stability for instance positively related to psychological adjustment (Ali et al., 2003) and both the interaction and work adjustment (Shaffer et al., 2006). Openness to experience predicted work adjustment (Shaffer et al., 2006) and, for expatriate spouses, related to psychological and socio-cultural adjustment (Ali et al., 2003). Extraversion, agreeableness and conscientiousness also positively relate to CCA (Searle \& Ward, 1990; Shaffer et al., 2006), although do not always contribute to the same domains of CCA. For example, agreeableness predicted interaction adjustment, whereas extraversion and conscientiousness were more relevant to general adjustment (Shaffer et al., 2006).

Drawing from the evolutionary personality psychology theory (Buss, 1991), the Big Five personality characteristics has been linked with universal adaptive mechanisms that allow individuals to adapt with and meet the demands of physical, social and cultural environments. These adaptive mechanisms include humans' ability to learn hierarchies in society (Extroversion), "their willingness to cooperate (Agreeableness), their capacity for reliable work and enduring commitment (Conscientiousness), their ability to handle stress (Emotional Stability), and their propensity for innovation or astuteness in solving problems (Openness, Intellect)" (Buss, 1991, cited in Caligiuri, 2000a, p.71). Hence, individuals who possess the appropriate personality trait expected to adjust effectively to new cultural contexts abroad (Caligiuri, 2000a). Further, Leiba-O'Sullivan (1999) indicated that personality, as a stable disposition is a vital intercultural competency to facilitate individual adaptation to new cultural setting.

Additionally, based on stress management theories of psychological stress (Cohen, 1988) perspective, since intercultural interactions involves a series of stress-provoking life changes that draw on adjustive resources and require coping responses; CCA, therefore, is conceptualized by successfully coping with change. Certain personality traits such as emotional stability, agreeableness and extraversion helps to negate psychological stress, thus leads to higher level of CCA (Black, 1990; Aryee et al., 1996; Wan, Hui \& Tiang, 2003). Broadly, it can be conclude that the Big Five personality is a valid predictor of CCA. In order to establish the relationship between personality and CCA, we have decided to test the presumed relationship as follows:

$\mathrm{H} 1$ : There is a positive relationship between personality and cross-cultural adjustment.

Specifically, (H1a) extraversion, (H1b) agreeableness, (H1c) conscientiousness, (H1d) openness to experience, and (H1e) emotional stability will relate positively to (i) general adjustment, (ii) interaction adjustment and (iii) work adjustment.

\section{Methodology}

\subsection{Sample}

The participants in the study were expatriates currently working and residing in Malaysia. Various Directories of International Business Chamber of Commerce/Business Councils in Malaysia (e.g., Directory of The American Malaysian Chamber of Commerce) and Directory of Foreign Companies in Malaysia used as a sampling frame 
of this study. Using the probability sampling technique of systematic sampling, a total of 500 mail and 500 online questionnaires distributed to intended respondents. Of these, 339 questionnaires replied. The initial response rate was $34 \%$, which is consistent with other typical response rates $(20-30 \%)$ in most expatriate studies (e.g., Harrison \& Shaffer, 2005). Out of 339, 7 were unusable responses, resulting in final sample of 332, representing a 33\% return rate. The sample included $252(75.9 \%)$ men and $80(24.1 \%)$ women. Participants age included $122(36.7 \%)$ between $42-52$ and $103(31.0 \%)$ between 31-41 years old. Participants marital status included 251 (75.6\%) married and 54 (16.3\%) unmarried. In terms of prior overseas experience, 251 (75.6) have previous international experience and $81(24.4 \%)$ have no experience. Participants job status included 169 $(50.9 \%)$ in managerial position and $163(49.1 \%)$ in non-managerial position. Participants education status included $119(35.8 \%)$ with degree and $85(25.6 \%)$ with masters degree. Distribution of sample by industry sector included $112(33.7 \%)$ working in service sector, $109(32.8 \%)$ in other sector and $84(25.3 \%)$ in manufacturing. Participants length of stay in Malaysia ranged from 2 to 24 years $(M=4.80, S D=3.40)$. Tenure with present organization ranged from 2 to 25 years $(M=7.25, S D=4.45)$. The participants came from various countries with majority 51 (15.4\%) are from India, 39 (11.7\%) from UK, 32 (9.6\%) from Australia, and 200 (63.3\%) from some other 42 countries.

\subsection{Instrumentation}

Four background variables (i.e. gender, prior overseas experience, length of stay in Malaysia and language proficiency) identified as correlates of expatriate attitudes and behaviors controlled in this study (Hechanova et al., 2003; Shaffer \& Harrison, 1998). This is to avoid the findings of this study from be spuriously attributed to various background characteristics.

The independent variable, personality measured with the 44-item, self-reported Big Five Inventory (BFI) adopted from John and Srivastava (1999). The scale includes eight items for extraversion, nine for agreeableness, nine for conscientiousness, eight for neuroticism, and ten for openness to experience personality dimension. Sample item include "I see myself as someone who has an assertive personality" for extraversion; "I see myself as someone who is helpful and unselfish with others" for agreeableness; "I see myself as someone who is a reliable worker" for conscientiousness; "I see myself as someone who can be moody" for neuroticism; and "I see myself as someone who is original, comes up with new ideas" for openness to experience personality. Respondents were asked to use a seven-point Likert-type scale range from strongly disagree (1) to strongly agree (7) to indicate the extent to which each item describes their characteristic. Cronbach's alpha for this scale was 0.83 (John \& Srivastava, 1999).

The dependent variable, CCA measured with 14-item, self-reported Expatriate Adjustment Scale adopted from Black and Stephens (1989). Seven items assessed general adjustment (e.g. housing, food, and shopping); four items assessed interactions adjustment (e.g. socializing with people from the host culture); and three items assessed work adjustment (e.g. job responsibilities and performance standards/expectations). Respondents asked to use a seven-point Likert-type scale to indicate the extent to which each item indicates their adjustment to various living and working conditions in Malaysia. Response choice alternatives ranged from 1 (very unadjusted) to 7 (completely adjusted). Cronbach's alphas for general adjustment, interactions adjustment, and work adjustment were $0.91,0.82$, and 0.86 respectively (Black \& Stephens, 1989).

\section{Results}

Table 1 presents the means, standard deviations, reliability coefficients, and bivariate correlations among the study variables. Personality was positively related to CCA $(r=0.28, p<0.05)$. Correlations between dimensions of personality and dimensions of CCA reveal that agreeableness personality was correlated positively with general, interaction and work adjustment ( $r$ ranges from 0.18 to 0.21 , all $p \mathbf{s}<0.05$ ). Extraversion personality correlated positively with general $(r=0.23, \mathrm{p}<0.05)$ and interaction adjustment $(r=0.11, \mathrm{p}<0.05)$. Conscientiousness personality was correlated positively with general $(r=0.13, \mathrm{p}<0.05)$ and work adjustment $(r$ $=0.26, \mathrm{p}<0.05)$. Openness to experience personality was correlated positively with general, interaction and work adjustment ( $r$ ranges from 0.16 to 0.20 , all $p s<0.05$ ). Emotional stability was correlated positively with general $(r=0.16, \mathrm{p}<0.05)$ and work adjustment $(r=0.22, \mathrm{p}<0.05)$ (opposite pole of neuroticism personality).

$\mathrm{H} 1$ predicted that there is a positive relationship between personality and CCA. A hierarchical regression conducted to test the hypothesis (See Table 2). When the control variables were entered in the first step, the regression model was statistically significant, $R^{2}=.167$, Adjusted $R^{2}=.157, F(4,327)=16.393, p<0.05$. Length of stay in Malaysia $(\beta=.231)$ and language proficiency $(\beta=.310)$ both $p \mathrm{~s}<0.05$ were positively related to CCA. When personality was added to the model in Step 2 , the full model was statistically significant, $R^{2}$ $=.240$, Adjusted $R^{2}=.228, F(5,326)=20.546, p<0.05$. Again, length of stay in Malaysia $(\beta=.244)$ and 
language proficiency $(\beta=.292)$ both $p$ s $<0.05$ were positively associated with CCA, indicating that those who had been in Malaysia for a longer period of time and proficient in language tended to have better CCA. Personality was statistically significant $(\beta=.277, p<0.05)$. This indicates that individuals with higher level of personality tended to have better CCA. This finding supports the hypothesis H1. In addition, the change in $\mathrm{R}^{2}$ between Step 1 and Step 2 was significant $\left(\Delta \mathrm{R}^{2}=.073, p<0.05\right)$ indicating that personality explains an additional 7.3 per cent of the variance in CCA, even when the effects of the control variables are statistically controlled.

To test the sub-hypotheses 1 it requires an examination on the relationship between dimensions of personality and dimensions of CCA. Again, a hierarchical regression analysis conducted (See Table 3). Agreeableness personality was positively associated with general $(\beta=.112)$ and interaction adjustment $(\beta=.160)$ both $p \mathrm{~s}<0.05$. This indicates that individuals with higher levels of agreeableness personality tended to have higher level of general and interaction adjustment. Extraversion personality was positively associated with general adjustment $(\beta=.149, p<0.05)$, indicating that higher the extraversion personality, higher the general adjustment will be. Conscientiousness $(\beta=.137)$ and openness to experience personality $(\beta=.145)$ both $p$ s $<0.05$ were positively associated work adjustment, indicating that those higher in conscientiousness and openness personality tended to have higher level of work adjustment. These findings support hypothesis H1a (i), H1b (i), (ii), H1c (iii) and H1d (iii).

The change in $\mathrm{R}^{2}$ between Step 1 and Step 2 was significant for all three dimensions of CCA, general $\left(\Delta \mathrm{R}^{2}\right.$ $=.067)$, interaction $\left(\Delta \mathrm{R}^{2}=.041\right)$ and work adjustment $\left(\Delta \mathrm{R}^{2}=.093\right)$ all $p \mathrm{~s}<0.05$. This indicates that agreeableness, extraversion, conscientiousness, neuroticism, and openness to experience personality together explain an additional 6.7, 4.1, and 9.3 per cent of the variance in general, interaction, and work adjustment respectively, even when the effects of the control variables are statistically controlled.

\section{Discussion and Conclusion}

The purpose of this paper is to enhance our knowledge on the individual determinant of CCA among expatriates assigned to Malaysia. Specifically, this study explored the affects of personality trait on CCA. The results indicated that after accounting for control variables of gender, prior overseas experience, duration of stay in the host country and language fluency, personality trait significantly related to CCA. In this study, greater general adjustment among expatriates is associated with greater extraversion and agreeableness personality. Greater interaction adjustment related to being greater agreeableness while greater work adjustment related to greater conscientiousness and openness to experience personality. In general, the findings of the present study are consistent with results of prior studies (e.g., Caligiuri, 2000b; Ward et al., 2004; Huang et al., 2005; Swagler \& Jome, 2005; Shaffer et al., 2006).

The significant positive relationship found between extraversion personality and general adjustment implies that greater the extraversion personality, greater the general adjustment will be. The results of this study is in line with findings of Huang et al. (2005) that being gregarious, assertive, active and talkative (Barrett \& Pietromonaco, 1997), extravert individuals will assert themselves to establish relationships with both host country nationals and other expatriates hence effectively learn the social culture of the host country. The cultural knowledge gained through the interaction process provides a framework for understanding and comparing different cultures (Johnson, Lenartowicz \& Apud, 2006) and in turn, facilitate the general adjustment to the new cultural environment in Malaysia. Agreeableness personality found positively related to general and interaction adjustment, hence implies that greater the agreeableness personality, greater the general and interaction adjustment will be. Shaffer et al. (2006) argued that individuals high on agreeableness personality generally have the tendency to get along well with others in interpersonal settings, hence, facilitate effective communication and relationship with host country nationals and other expatriates. This in turn, should alleviate the stress associated with adapting to various aspects of the new cultural environment. As expected, conscientiousness personality found positively related to work adjustment. This implies that greater the conscientiousness personality, greater the work adjustment will be. Shaffer et al. (2006) contended that motivated to achieve, individual high on conscientiousness personality more likely to spend time on tasks and meet job expectations even in the face of obstacles or personal problems (Ones \& Viswesvaran, 1997), hence such task-oriented behaviors may result in better work adjustment. In line with the prediction, openness to experience personality positively related to work adjustment. This implies that greater the openness personality, greater the work adjustment will be. According to Huang et al. (2005), individuals who defined as open to experience are generally open minded, curious, original in thought, intelligent, imaginative and non-judgmental (Mount \& Barrick, 1995), hence they tend to be more curious and eager to learn to adapt to work and non-work related aspects in a new cultural environment in Malaysia. 
Given these results, there are few implications for organizations and individuals considering international assignments. The significant positive relationship between personality and CCA suggest that personality is important stable intercultural competency in enhancing expatriate CCA (Leiba-O'Sullivan, 1999). Expatriating firms can consider the use of selection methods that include testing for personality traits of agreeableness, extraversion, conscientiousness, and openness to experience in finding prospective expatriates for international assignments. However, it is necessary to consider personality traits in relation to host country culture. The findings of this study have provided evidence that individuals high on agreeableness, extraversion, conscientiousness, and openness to experience personality adjust effectively to various aspects of new cultural environment when assigned to host culture predominantly collective in nature such as Malaysia (Hofstede, 1991). In addition to selection, cross-cultural training is also an available HR intervention to improve the likelihood of expatriate CCA. MNCs should think of selection based on personality as the precursor to cross-cultural training. That is, MNCs should identify those expatriate candidates with the requisite personality characteristics, and then offer cross-cultural training to those identified. Cross-cultural training may only be effective when the expatriates are predisposed to success in the first place.

This study has certain limitations that provide venues for future research. First, CCA is not the only criterion for expatriate effectiveness. Other important criterion such as job performance, job satisfaction, organizational commitment, and turnover intention should also be included in the future study. Second, we acknowledge that some concerns might exist in that self-reported measures have social desirability and common method bias problem. Therefore, future research should include assessment from multiple sources including peers, subordinates, and superiors. Third, a cross-sectional study design restricts the ability to prove a cause-effect relationship. Future research should consider longitudinal study if replication of this study is to establish the predictive functions of personality trait over time and space. Third, this study did not consider the possible moderating effects of the contextual factors on the predictor-outcome relationships. Potential moderators such as cultural distance (i.e. home vs. host country), assignment type (e.g., managerial vs. non-managerial), assignment tenure and prior overseas experience may help to further enhance our understanding about the phenomenon under investigation.

\section{References}

Ali, A., Van der Zee, K. \& Sanders, G. (2003). Determinants of intercultural adjustment among expatriate spouses. International Journal of Intercultural Relations, Vol.27, pp.563-580.

Allerton, H. (1997). Expatriate gaps. Training \& Development, July, 7-8.

Aryee, S., Chay, Y. W. \& Chew, J. (1996). An investigation of the willingness of managerial employees to accept an expatriate assignment. Journal of Organizational Behavior, Vol.17(3), pp.267-283.

Aycan Z. \& Kanungo R.N. (1997). Current issues and future challenges in expatriate management. In Saunders DM, Aycan Z (Eds.), New approaches to employee management (Vol. 4, pp. 245-260). Greenwich, CT: JAI Press.

Barrett, L.F. \& Pietromenaco, P.R. (1997). Accuracy of the Five-factor Model in Predicting Perceptions of Daily Social Interactions. Personality and Social Psychology Bulletin, 23(11), 1173-1187.

Barrick, M.R., \& Mount, M.K. (1991). The Big Five personality dimensions and job performance. Personnel Psychology, 41, 1-26.

Bhaskar-Shrinivas, P., Harrison, D.A., Shaffer, M.A., \& Luk, D.M. (2005). Input-based and time-based models of international adjustment: Meta-analytic evidence and theoretical extensions. Academy of Management Journal, 48, 259-281.

Black, J.S. (1990). The relationship of personal characteristics with the adjustment of Japanese expatriate managers. Management International Review, 30,119-134.

Black, J.S., \& Gregersen, H.B (1999). The right way to manage expatriates. Harvard Business Review, 77, 52-63.

Black, J.S., Mendenhall, M., \& Oddou, G. (1991). Toward a comprehensive model of international adjustment: an integration of multiple theoretical perspectives. Academy of Management Review, 16 (2), 291-317.

Black, J.S., \& Stephens, G.K. (1989). The influence of the spouse on American expatriate adjustment and intent to stay in Pacific Rim overseas assignments. Journal of Management, 15, 529-544.

Buss, D.M. (1991). Evolutionary personality psychology. In M.R. Rosenzweig \& L.W. Porter (Eds.), Annual Review of Psychology, Vol. 42, pp.459-492. Palo Alto, CA: Annual Reviews Inc. 
Caligiuri P.M. (1997). Assessing expatriate success: Beyond just “being there.” In Saunders DM, Aycan Z (Eds.), New approaches to employee management (Vol. 4, pp. 117-140). Greenwich, CT: JAI Press.

Caligiuri, P.M. (2000a). The Big Five personality characteristics as predictors of expatriate's desire to terminate the assignment and supervisor-rated performance. Personnel Psychology, 53, 67-88.

Caligiuri, P.M. (2000b). Selecting expatriates for personality characteristics: A moderating effect of personality on the relationship between host national contact and cross-cultural adjustment. Management International Review, 40(1), 61-80.

Cohen, S. (1988). Aftereffects of stress on human performance and social behavior: A review of research and theory. Psychological Bulletin, Vol. 88, pp. 82-108.

Costa, P.T., Jr., \& McCrae, R.R. (1992). Revised NEO Personality Inventory and NEO Five Factor Inventory: Professional Manual. Odessa, FL: PAR.

Dalton, M., \& Wilson, M. (2000). The relationship of the five-factor model of personality to job performance for a group of Middle Eastern expatriate managers. Journal of Cross-Cultural Psychology, 31, 250-258.

Digman, J.M. (1990). Personality structure: Emergence of the five-factor model. In M. R. Rosenzweig\& L.W. Porter (Eds.), Annual review of psychology (Vol. 41, pp. 417-440). Palo Alto, CA: Annual Reviews.

Digman, J.M. (1997). Higher-order factors of the big five. Journal of Personality and Social Psychology, 73, 1246-1256.

GMAC Global Relocation Services. The 2008 Global Relocation Trends Survey Report, GMAC Global Relocation Services LLC.

Gregersen, H.B., \& Black, J.S. (1990). A multifaceted approach to expatriate retention in international assignments. Group and Organization Studies, 15, 461-485.

Harrison, D.A., \& Shaffer, M.A. (2005). Mapping the criterion space for expatriate success: Task-based and relationship-based performance, effort and adaptation. International Journal of Human Resources Management, $16,1454-1474$.

Hechanova, R., Beehr, T.A., \& Christiansen, N.D. (2003). Antecedents and consequences of employees' adjustment to overseas assignments: A meta-analytic review. Applied Psychology, 52, 213-236.

Hofstede, G. (1991). Cultures and organizations: Software of the mind. London: McGraw-Hill.

Hogan, J., \& Hogan, R. (1986). Hogan Personnel Selection Series Manual. Tulsa, OK: Hogan Assessment Systems.

Hogan, J., \& Ones, D.S. (1997). Conscientiousness and integrity at work. In R. Hogan, J. A. Johnson, \& S. R. Briggs (Eds.), Handbook of personality psychology (pp. 849-870). New York: Academic Press.

Hough, L.M. (1992). The "Big Five" personality variables-construct confusion: Description versus prediction. Human Performance, 5, 139-156.

Huang, T.J., Chi, S.C., \& Lawler, J.J. (2005). The relationship between expatriate's personality traits and their adjustment to international assignments. International Journal of Human Resource Management, 16, 1656-1670.

Immigration Department of Malaysia (2008). Expatriate Statistical Report Dated from 01/01/2007 to 31/12/2007. Employment Pass Section, Immigration Department, Malaysia.

John, O.P., \& Srivastava, S. (1999). The Big Five trait taxonomy: History, measurement, and theoretical perspective. In L. A. Pervin \& O. P. John (Eds.), Handbook of personality: Theory and research (2nd ed., pp. 102-138). New York: Guilford.

Johnson, J.P., Lenartowicz, T., \& Apud, S. (2006). Cross-cultural competence in international business: towards a definition and a model. Journal of International Business Studies, 37, 525-543.

Kim, K., \& Slocum, J.W. (2008). Individual differences and expatriate assignment effectiveness: The case of U.S. based Korean expatriates. Journal of World Business, 43, 109-126.

Kraimer, M.L., Wayne, S.J., \& Jaworski, R.A. (2001). Sources of support and expatriate performance: The mediating role of expatriate adjustment. Personnel Psychology, 54, 71-99.

Laursen, B., Pulkkinen, L., \& Adams, R. (2002). The antecedents and correlates of agreeableness in adulthood. Developmental Psychology, 38, 591-603.

Leiba-O'Sullivan, S. (1999). The distinction between stable and dynamic cross-cultural competencies: implications for expatriate trainability. Journal of International Business Studies, 30(4), 709-725. 
Maertz, C.P., Hassan, A., \& Magnusson, P. (2009). When learning is not enough: A process model of expatriate adjustment as cultural cognitive dissonance reduction. Organizational Behavior and Human Decision Processes, 108, 66-78.

Malaysian Industrial Development Authority (2009). Industry leaders: Malaysia offers significant cost advantage for regional establishments. [Online] Available: http://www.mida.gov.my (October 6, 2009).

McCrae, R.R., \& Costa, P.T., Jr. (1989). Reinterpreting the Myers-Briggs Type Indicator from the perspective of the five-factor model of personality. Journal of Personality, 57, 17-40.

McEvoy, G.M., \& Parker, B. (1995). Expatriate adjustment: Causes and consequences. In Selmer J (Ed.), Expatriate management: New ideas for international business (pp. 97-114). Westport, CT: Quorum Books.

Mol, S.T., Born, M.P., Willemsen, M.E., \& Van Der Molen, H.T. (2005). Predicting expatriate job performance for selection purposes: A quantitative review. Journal of Cross-Cultural Psychology, 36(5), 590-620.

Mount, M.K., \& Barrick, M.R. (1995). The Big Five personality dimensions: Implications for research and practice in human resources management. In K. M. Rowland \& G. Ferris (Eds.), Research in personnel and human resources management (Vol. 13, pp. 153-200). Greenwich, CT: JAI Press.

Naumann, E. (1993). Antecedents and consequences of satisfaction and commitment among expatriate managers. Group and Organization Management, 18(2), 153-187.

Ones, D.S., \& Viswesvaran, C. (1997). Personality determinants in the prediction of aspects of expatriate job success. In Z. Aycan (Ed.), New approaches to employee management: Vol. 4. Expatriate management: Theory and research (pp. 63-92). Stamford, CT: JAI Press.

Rusting, C.L., \& Larsen, R.J. (1998). Personality and cognitive processing of affective information. Personality and Social Psychology Bulletin, 24, 200-213.

Searle,W. \& Ward, C. (1990). The prediction of psychological and sociocultural adjustment during cross-cultural transitions. International Journal of Intercultural Relations, 14, 449-464.

Shaffer, M.A., \& Harrison, D.A. (1998). Expatriates' psychological withdrawal from international assignments: Work, nonwork, and family influences. Personnel Psychology, 51, 87-118.

Shaffer, M.A., Harrison, D.A., \& Gilley, K.M. (1999). Dimensions, determinants, and differences in the expatriate adjustment process. Journal of International Business Studies, 30, 557-581.

Shaffer, M.A., Harrison, D.A., Gregersen, H., Black, J.S., \& Ferzandi, L.A. (2006). You can take it with you: Individual differences and expatriate effectiveness. Journal of Applied Psychology, 91, 109-125.

Shay, J.P., \& Baack, S. (2006). An empirical investigation of the relationships between modes and degree of expatriate adjustment and multiple measures of performance. International Journal of Cross Cultural Management, 6 (3), 275-294.

Storti, C. (2001). The Art of Crossing Borders. Nicholas Brealey \& Intercultural Press: London.

Swagler, M.A., \& Jome, L.M. (2005). The effects of personality and acculturation on the adjustment of North American sojourners in Taiwan. Journal of Counseling Psychology, 52 (4), 527-536.

Tahir, A.H.M., \& Ismail, M. (2007). Cross-cultural Challenges and Adjustment of Expatriates: A Case Study in Malaysia. Turkish Journal of International Relations, 6 (3\&4), 72-99.

Takeuchi, R., Yun, S., \& Tesluk, P.E. (2002). An examination of crossover and spillover effects of spousal and expatriate cross-cultural adjustment on expatriate outcomes. Journal of Applied Psychology, 87, 655-666.

Tung, R. (1982). Selection and training procedures of U.S., European and Japanese Multinationals. California Management Review, 25, 57-72.

Tung, R. (1987). Expatriate Assignments: Enhancing Success and Minimizing Failure. Academy of Management Executive, 1(2), 117-126.

Wan, D., Hui, T. K. \& Tiang, L (2003). Factors affecting Singaporeans' acceptance of international postings. Personnel Review, Vol.32(6), pp.711-732.

Ward, C., Leong, C.H., \& Low, M. (2004). Personality and sojourner adjustment: An exploration of the Big Five and the cultural fit proposition. Journal of Cross-Cultural Psychology, 35, 137-151. 
Table 1. Descriptive statistics, reliability coefficients and correlations $(\mathrm{N}=332)$

\begin{tabular}{|c|c|c|c|c|c|c|c|c|c|c|c|c|c|c|c|c|}
\hline Variable & Mean & $\mathrm{SD}$ & 1 & 2 & 3 & 4 & 5 & 6 & 7 & 8 & 9 & 10 & 11 & 12 & 13 & 14 \\
\hline 1. Gender & 0.76 & 0.43 & - & & & & & & & & & & & & & \\
\hline 2. Prior experience & 0.76 & 0.43 & $0.12^{*}$ & - & & & & & & & & & & & & \\
\hline 3. Length of stay & 4.80 & 3.40 & 0.03 & -0.03 & - & & & & & & & & & & & \\
\hline 4. Language & 3.57 & 0.70 & $-0.16^{* *}$ & $0.21^{* *}$ & $0.16^{* *}$ & - & & & & & & & & & & \\
\hline 5. Personality & 4.92 & 0.33 & -0.08 & $0.20 * *$ & -0.04 & $0.11^{*}$ & $(0.71)$ & & & & & & & & & \\
\hline 6. Adjustment & 5.75 & 0.58 & 0.01 & 0.03 & $0.28^{* *}$ & $0.33^{* *}$ & $0.28 * *$ & $(0.87)$ & & & & & & & & \\
\hline 7. Agreeableness & 5.48 & 0.69 & 0.32 & $0.15^{* *}$ & -0.02 & 0.09 & $0.62^{* *}$ & $0.24^{* *}$ & $(0.74)$ & & & & & & & \\
\hline 8. Extraversion & 4.91 & 0.81 & -0.09 & $0.19 * *$ & -0.07 & $0.16^{* *}$ & $0.62 * *$ & $0.20^{* *}$ & $0.26^{* *}$ & $(0.76)$ & & & & & & \\
\hline 9. Conscientiousness & 5.46 & 0.73 & 0.08 & $0.14^{*}$ & 0.01 & -0.06 & $0.69^{* *}$ & $0.18^{* *}$ & $0.44 * *$ & $0.34 * *$ & $(0.77)$ & & & & & \\
\hline 10. Openness & 5.36 & 0.56 & -0.05 & $0.16^{* *}$ & -0.02 & $0.18^{* *}$ & $0.67^{* *}$ & $0.24^{* *}$ & $0.20^{* *}$ & $0.30^{* *}$ & $0.35^{* *}$ & $(0.73)$ & & & & \\
\hline 11. Neuroticism & 3.16 & 0.82 & $-0.15^{* *}$ & $-0.17 * *$ & -0.00 & -0.09 & $-0.22^{* * *}$ & $-0.20^{* *}$ & $-0.44 * *$ & $-0.44^{* *}$ & $-0.50 * *$ & $-0.18^{* *}$ & $(0.76)$ & & & \\
\hline 12. GA & 5.71 & 0.70 & -0.05 & 0.02 & $0.21^{* *}$ & $0.31^{* *}$ & $0.24^{* *}$ & $0.87^{* *}$ & $0.19^{* *}$ & $0.23^{* *}$ & $0.13^{*}$ & $0.20^{* *}$ & $-0.16^{* *}$ & $(0.83)$ & & \\
\hline 13. IA & 5.66 & 0.76 & 0.00 & -0.03 & $0.28^{* *}$ & $0.32 * *$ & $0.17^{* *}$ & $0.79^{* *}$ & $0.18^{* *}$ & $0.11^{*}$ & 0.07 & $0.16^{* *}$ & -0.09 & $0.55^{* *}$ & $(0.86)$ & \\
\hline 14. WA & 5.98 & 0.80 & $0.15^{* *}$ & 0.08 & $0.16^{* *}$ & 0.06 & $0.22^{* *}$ & $0.55^{* *}$ & $0.21^{* *}$ & 0.07 & $0.26^{* *}$ & $0.20^{* *}$ & $-0.22^{* *}$ & $0.24^{* *}$ & $0.29^{* *}$ & $(0.90)$ \\
\hline
\end{tabular}

Notes: $* p<.05 . \quad$ * $\quad$ GA $=$ general adjustment; IA=interaction adjustment; WA=work adjustment

Coefficient alphas are presented along the diagonal

Table 2. Results of the Hierarchical Regression Analysis with Personality as a Predictor of Cross-Cultural Adjustment $(\mathrm{N}=332)$

\begin{tabular}{llllllll}
\hline & \multicolumn{3}{c}{ Step 1 } & \multicolumn{3}{c}{ Step 2 } \\
Variable & $\beta$ & $t$ & $p$ & $\beta$ & $t$ & $p$ \\
\hline Gender & .063 & 1.214 & .226 & .088 & 1.760 & .079 \\
Prior overseas experience & -.038 & -.719 & .472 & -.091 & -1.779 & .076 \\
Length in Malaysia & .231 & 4.508 & .000 & .244 & 4.960 & .000 \\
Language proficiency & .310 & 5.804 & .000 & .292 & 5.701 & .000 \\
Personality & - & - & - & .277 & 5.578 & .000 \\
& & & & & & & \\
\hline
\end{tabular}

Note: Gender ana prior experience are aummy-coaea categorıcaı varıabıes.

Step $1 R^{2}=.167$, Adjusted $R^{2}=.157, F(4,327)=16.393, p=.000 ;$ Step $2 R^{2}=.240$, Adjusted $R^{2}=.228, F(5,326)=20.546, p=.000$, $\Delta \mathrm{R}^{2}=.073, p=.000$.

Table 3. Results of the Hierarchical Regression Analysis between Dimensions of Personality and Dimensions of Cross-Cultural Adjustment $(\mathrm{N}=332)$

\begin{tabular}{|c|c|c|c|c|c|c|}
\hline \multirow[t]{2}{*}{ Variable } & \multicolumn{2}{|c|}{ General } & \multicolumn{2}{|c|}{ Interaction } & \multicolumn{2}{|l|}{ Work } \\
\hline & $\begin{array}{l}\text { Step } 1 \\
\beta(t)\end{array}$ & $\begin{array}{l}\text { Step } 2 \\
\beta(t)\end{array}$ & $\begin{array}{l}\text { Step } 1 \\
\beta(t)\end{array}$ & $\begin{array}{l}\text { Step } 2 \\
\beta(t)\end{array}$ & $\begin{array}{l}\text { Step } 1 \\
\beta(t)\end{array}$ & $\begin{array}{l}\text { Step } 2 \\
\beta(t)\end{array}$ \\
\hline Gender & $-.004(-.084)$ & $.008(.147)$ & $.058(1.118)$ & $.067(1.276)$ & $.149(2.685)^{* *}$ & $.126(2.326)^{*}$ \\
\hline Prior experience & $-.031(-.576)$ & $-.089(-1.672)$ & $-.093(-1.780)$ & $-.132(-2.505)^{*}$ & $.055(.981)$ & $.001(.010)$ \\
\hline Length of stay & $.167(3.181)^{* *}$ & $.186(3.631)^{* * *}$ & $.230(4.490)^{* * *}$ & $.244(4.803)^{* * *}$ & $.146(2.663)^{* *}$ & $.146(2.769)^{* *}$ \\
\hline Language & $.291(5.327)^{* * *}$ & $.251(4.566)^{* * *}$ & $.314(5.879)^{* * *}$ & $.281(5.165)^{* * *}$ & $.050(.880)$ & $.034(.595)$ \\
\hline Agreeableness & & $.112(1.912)^{*}$ & & $.160(2.764)^{* *}$ & & $.096(1.600)$ \\
\hline Extraversion & & $.149(2.521)^{*}$ & & $.057(.972)$ & & $-.072(-1.186)$ \\
\hline Conscientiousness & & $.015(.236)$ & & $-.015(-.237)$ & & $.137(2.073)^{*}$ \\
\hline Neuroticism & & $-.011(-.165)$ & & $.024(.373)$ & & $-.094(-1.422)$ \\
\hline Openness & & $.096(1.718)$ & & $.094(1.696)$ & & $.145(2.519)^{*}$ \\
\hline $\mathrm{R}^{2}$ & .126 & .193 & .169 & .209 & .053 & .146 \\
\hline Adjt $R^{2}$ & .116 & .170 & .159 & .187 & .041 & .122 \\
\hline$\Delta \mathrm{R}^{2}$ & & $.067^{* * *}$ & & $.041 * *$ & & $.093 * * *$ \\
\hline $\mathrm{F}$ & $(4,327)$ & $(9,322)$ & $(4,327)$ & $(9,322)$ & $(4,327)$ & $(9,322)$ \\
\hline & $11.809 * * *$ & $8.555^{* * *}$ & $16.592 * * *$ & $9.476 * * *$ & $4.531 * *$ & $6.097 * * *$ \\
\hline
\end{tabular}

Gender and prior experience are dummy-coded categorical variables 